\title{
Oxygen-ozone therapy in prevention and rehabilitation of myocardium infarct
}

\author{
Sergio Pandolfi, ${ }^{1,2}$ Angelo Zammitti, ${ }^{1,2}$ Marianno Franzini, ${ }^{1,3}$ Vincenzo Simonetti, ${ }^{1,4}$ William Liboni, ${ }^{5}$ \\ Luigi Valdenassi, ${ }^{1,3}$ Filippo Molinari ${ }^{6}$
}

${ }^{1}$ Scientific Society of Oxygen-Ozone Therapy (SIOOT), Gorle (BG); ${ }^{2}$ Villa Mafalda Nursing Home, Rome; ${ }^{3}$ Department of Internal Medicine and Medical Therapy, Master in Oxygen-Ozone Therapy, University of Pavia; ${ }^{4}$ Kaos non-profit Association, Caselle Torinese (TO); ${ }^{5}$ Un Passo Insieme Onlus Foundation, Valdellatorre (TO); ${ }^{6}$ Department of Electronics and Telecommunications, Politecnico di Torino, Turin, Italy

\begin{abstract}
In 1991, Prof. Lettieri (Naples, Federico II University) using Great Ozonated Blood Auto Infusion (GAE) treated patients having acute myocardium infarct, he had good results concerning pain and prognosis. Oxygen-ozone therapy is protective for ischemic cardiopathy. In 1996, oxygen-ozone therapy was used in relapse myocardium infarct prevention, showing an important factor against infarct relapse. Ozone has an important anti-inflammatory and rheological action, even if it is a strong oxidant. Paradoxically ozone activates cells antioxidant system, activates cells enzymatic function against free radicals and increases DNA antioxidant enzyme transcription. Ozone also activates redoxine system, reduce pro inflammatory cytokines II $1 \beta$, TNFX, modulate NF$\mathrm{KB}$ system, reduce platelet aggregation and stimulate different
\end{abstract}

Correspondence: Sergio Pandolfi, Scientific Society of Oxygen-Ozone Therapy (SIOOT), Via Don Luigi Sturzo 2, 24020 Gorle (BG), Italy. Tel.: 035.19910105.

E-mail: info@ossigenoozono.it

Key words: Oxygen-ozone therapy; ischemic cardiopathy; myocardium infarct.

Contributions: the authors contributed equally.

Conflict of interest: the authors declare no potential conflict of interest.

Conference presentation: part of this paper was presented at the 5th International Congress on Oxygen-Ozone Therapy - Innovation and sharing to grow, 2018 March 16-18, Pontifical Faculty Seraphicum 1, via Serafico, Rome, Italy.

Received for publication: 20 April 2018.

Accepted for publication: 21 April 2018.

CC Copyright S. Pandolfi et al., 2018

Licensee PAGEPress, Italy

Ozone Therapy 2018; 3:7512

doi:10.4081/ozone.2018.7512

This article is distributed under the terms of the Creative Commons Attribution Noncommercial License (by-nc 4.0) which permits any noncommercial use, distribution, and reproduction in any medium, provided the original author(s) and source are credited. growth factor release. Because of the above skills, oxygen-ozone therapy helps to prevent ischemic cardiopathy and post infarcted rehabilitation. A mixture of ozone and oxygen administration has been evaluated on myocardium damaged tissues after an experimental ischemic event and myocardium reperfusion. Infarct damage can be counteract using pre- treatment with oxygen-ozone gaseous mixture. All our cardiopath patients treated with GAE have had an emo dynamic benefit, left ventricle ejection fraction improvement. Patients also improved aritmologic aspect with atrial fibrillation disappearance, enhance or disappearance of different comorbidity that often cardiopath/ischemic patients suffer.

\section{Introduction}

Ozone therapy in patients affected by myocardial infarction ${ }^{1-13}$ has been tested in Italy since the 90s when Prof. Biagio Lettieri treated by self ozone-infused blood infusion some patients with myocardial infarction in the acute phase, ${ }^{2}$ finding favorable results in terms of pain and prognosis and to prevent recurrence of the infarct to the myocardium. ${ }^{3}$ Ozone exerts an important anti-inflammatory and rheological activity, despite being a strong oxidant, due to paradoxical effect activates the cellular antioxidant system ${ }^{4,7-9}$ by modulating the endogenous protective enzymatic functions of cells against the radical forms, increasing the transcription at the DNA level of antioxidant enzymes. Activates the redoxin system, reduces pro-inflammatory cytokine II $1 \beta, \mathrm{TN}^{5}$ modulates the NF$\mathrm{KB}$ system, ${ }^{6}$ reduces platelet aggregation and stimulates the release of various growth factors. ${ }^{6-9}$ The effects of the acute administration of an oxygen-ozone mixture on myocardial tissue damage following an experimental ischemia and myocardial reperfusion event were assessed ${ }^{10}$ and it was found that the infarct lesion can be counteracted by pretreatment with the administration of the gaseous mixture of oxygen-ozone systemically, because it reduces the size of the necrotic area and the inflammatory and necrosis marches. An experimental study has documented that the systemic treatment with ozone increases eNOS activity and activates the recruitment of endothelial progenitor cells from the medulla, which has a reparative action in the infarcted zones. ${ }^{11}$ Oxygen-ozone therapy can reduce restenosis after implantation of metal stents due to its antioxidant and anti-inflammatory properties. ${ }^{12}$ Recurrence of stenosis, restenosis, or poor re-endothelialization may occur after a percutaneous trans-luminal coronary angioplasty, even using drugeluting stents for its anti-inflammatory and antioxidant properties. Oxygen ozone therapy improves the FE of the left ventricle in the infarcted pediatric patients. ${ }^{1,13}$ 


\section{Materials and Methods}

Ozone is a gas characterized by instability, naturally present in the body and in the atmosphere. Its administration in the body determines an initial and transitory stress oxidative that the reducing oxide systems of blood and plasma, cooperating with each other and contrasting. ${ }^{4,7-9,13}$ Obviously the therapeutic concentrations of ozone never exceed the antioxidant potential of the blood. Ozone in contact with plasma reacts instantly with antioxidant systems (especially uric acid, ascorbic acid, GSH, cysteine, albumin) therefore only a small part of the initial dose reacts with polyunsaturated fatty acids. , $7-9^{-9}$

Therefore the potential energy of the ozone is transferred to two main messengers, such as $\mathrm{H}_{2} \mathrm{O}_{2}$, 4-hydroxynonenal (4HNE) and trans-4-hydroxyzyxal (HHE) aldehyde molecules. Given the high reactivity of the ozone these reactions happen in a few seconds, and usually a few minutes are sufficient of contact between blood and oxygen-ozone mixture because ozone is completely exhausted e oxygen saturates the hemoglobin system, dissolving in plasma. Antioxidant systems are mostly reintegrated within 20 minutes after exposure to the gas mixture. ${ }^{4,7-9}$

Deionized $\mathrm{H}_{2} \mathrm{O}_{2}$ quickly enters all blood cells and makes the following changes. In the erythrocytes it activates glycolysis, increasing intracellular concentrations of ATP and 2.3 DPG. This translates into a shift to the right of the hemoglobin dissociation curve, which therefore more easily releases oxygen to the peripheral tissues. ${ }^{7-9}$ In the leukocytes the phagocytic activity of neutrophils is increased. In lymphocytes and macrophages, the intracellular patterns of LKB, one of the components of NFkB, are activated. The trimer, degraded in the proteasome in hetero dimer $\mathrm{p} 50$ p65, can activate the transcription of more than 100 genes. Interleukins and various acute phase proteins are produced, as well as IFN and TNF $\alpha .4,7-9,15$ PDGF AB, TGFB1 and growth factors are produced in the platelets. Aldehydes, reacting with GSH, carnosine and, above all, albumin, are transported in various body tissues. The toxicity of $4 \mathrm{HNEe}$ HHE is counteracted by compensation mechanisms such as detoxification, dilution and excretion; these compounds, in fact, recognized as oxidizing agents, determine a response from the body that produces SOD, heme-oxygenase, G6PDH and other powerful antioxidants. The aldehydes also stimulate the production of endothelial Nos, 4,7-9,15 improving peripheral perfusion and tissue oxygenation. Furthermore, in a randomized clinical trial of 140 patients, 70 of whom underwent ozone therapy and 70 as a control group, the haematochemical parameters showed a decrease in Oxygen Reactive Metabolites $(300 \pm 10.1$ UCARR at 12 months compared to an initial value of $380 \pm 10.4$ UCARR, $\mathrm{P}<0.05)$ and an increase in the values of the Biological Antioxidant Potential of plasma (2100 \pm 34.8 micromoles/vitamin C after 12 months compared to the initial value of $1610 \pm 36,2$, $\mathrm{P}<0.05$ ) in the treated patients compared to the control group. These data demonstrate that self ozone-driven blood infusion plays a role in reducing oxidative stress by stimulating the production of antioxidant enzymes via the endogenous route.

Oxygen ozone therapy in patients with ischemic heart disease or those affected by myocardial infarction, ${ }^{1-3,13}$ has been tested in Italy since 1991 when Prof. Biagio Lettieri, Ordinary of Anesthesia and Reanimation of Federico II University, Naples, treated some patients with acute myocardial infarction by means of self blood ozone injection, ${ }^{2}$ finding favorable results in terms of pain and prognosis. In 1996 ozone therapy oxygen was used in the prevention of recurrence of the infarct to the myocardium highlighting a significant protection against relapse of infarction. ${ }^{3}$ Subsequently, work on guinea pigs showed that rats subjected to ischemia and myocardial reperfusion, pretreated with a gaseous mixture of oxygen and ozone, showed less ischemic areas and better indices of cardiac function than those not treated with ozone. ${ }^{10,16}$ The animals were treated with an oxygenozone mixture of 100, 150 and $300 \mu \mathrm{g} / \mathrm{kg}$ infused intraperitoneally one hour before ischemic damage. The size of the infarct area, the necrosis markers and tissue damage were measured, lanitrotyrosine, CD68, CD8, CD4 and caspase-3. The results showed a smaller size of the infarct area in pretreated rats with the insufflation of the oxygen-ozone mixture and the parallel decrease of the tissue levels of nitrotyrosine and the markers of inflammation (CD68) and of the immune response (CD8 and CD4). These data indicate that the damage associated with myocardial ischemia and reperfusion can be counteracted by pretreatment by administration of the oxygen-ozone gaseous mixture by systemic route. Other more recent studies ${ }^{11}$ have shown that after a myocardial infarction, the levels of Endothelial Progenitor Cells are reduced in the myocardium. These cells are derived from the bone marrow and are aimed at mobilizing, migrating and differentiating into local endothelial cells and forming a cellular reserve capable of repairing endothelial damage. Strategies to increase to increase endothelial progenitor cells in an ischemic heart seem to improve the neovascularization of ischemic tissue, and could improve myocardial blood flow by decreasing the ischemia damage. An experimental animal study ${ }^{11}$ has shown that oxygenozone protects the heart from acute myocardial infarction thanks to the local increase of eNOS activity and the recruitment of endothelial progenitor cells.

It has been recently evaluated that oxygen-ozone therapy can reduce subsequent restenosis plant of metal stents in pigs thanks to

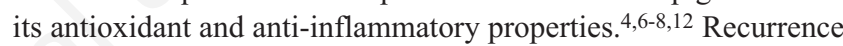
of stenosis, restenosis, or poor re-endothelialization may occur after percutaneous trans-luminal coronary angioplasty, even using drug-eluting stents, due to inflammation and oxidative stress at the endothelium. Twelve pigs Male landraces $(51 \pm 9 \mathrm{~kg})$ underwent trans-luminal percutaneous metal stent implants in the circumflex coronary arteries under heparin infusion and fluoroscopic guidance, using standard techniques. The randomized study ${ }^{12}$ was performed with 6 pigs submitted to oxygen-ozone therapy and 6 other pigs receiving placebo treatment. Before applying the stent (24 hours before) and twice a week for 30 days after the stent, the venous blood was collected, ozonated and re-infused. The same procedure was performed in the placebo group with the exception of ozonation. Both groups received anticoagulant treatment. Histopathology and immunohistochemistry were performed. The results of the study showed a severe inflammatory reaction and restenosis with increased immunohistochemical expression of thioredoxin-1 in the placebo group at 30 days after surgery. In the opposite way, ozone therapy significantly reduced the inflammatory reaction and restenosis, and showed no increase in the Trx-1 immunohistochemical expression 30 days after surgery. Ozonated autohemotherapy surprisingly reduced restenosis to 30 days from PTCA with BMS in pigs. ${ }^{12}$ Stimulation of the redoxin system, superoxide dismutase, catalase, carnosine, albumine, heme-oxygenase, G6PDH, due to ozone pretreatment has neutralized oxidative damage by increasing post-ischemic antioxidant capacity, reducing the risk of stent restenosis.

The data found by prof. Lettieri and Chiefari in the $1990 \mathrm{~s}^{2,3}$ confirmed by all experimentations on experimental animals carried out subsequently ${ }^{10-12,16}$ and in vivo recently ${ }^{13}$ show the possibility of recovery of myocardial tissue affected by an ischemic event has a more favorable evolution as it is more timely treatment with GAE meaning timely treatment in the first eight hours of the ischemic event. 


\section{Results and Discussion}

The study in question on two groups of patients (group A, treated with GAE within 8 hours from the ischemic event in addition to traditional therapies - group B, treated only with traditional therapies) has had different evolutions, better in the group of patients treated with GAE. This clinical data is supported by: ECG evaluations, enzymatic values, from the calculation of the FE, done in the peri-infarct phase because the mechanical event precedes the electrical one. Treatment with GAE, in the early phase of the ischemic event - within the first 8 hours - allows a significant increase in the perfusion of the area surrounding the area of necrosis that is in the acute phase of myocardial infarction in the face of a double fate: the danger that reactive vasoconstriction and the presence of toxic substances released from the area of necrosis accentuate ischemia until it results in the enlargement of the infarct. It is possible, through the preferential channels of the microcirculation, activated by the mixture of $\mathrm{O}_{2}-\mathrm{O}_{3}$, to bring low viscosity blood into the ischemic zone by operating the reperfusion recovery of this at risk zone. The action of the $\mathrm{O}_{2}-\mathrm{O}_{3}$ mixture, which activates the antioxidant systems, determines in the erythrocytes greater plasticity, an activation of glycolysis, an increase in ATP and 2.3 DPG concentrations with better tissue oxygenation, an increase in eNOS production and stimulation of substances that moderate the acute phase reaction. For these elements it is believed that the timely treatment - within the first 8 hours - of an acute ischemic event, has in GAE an adjuvant to myocardium infarct classic therapies.

\section{Conclusions}

Ozone therapy by GAE protects the heart of patients suffering from ischemic heart disease and is useful in the acute phase of infarction and in the rehabilitation of patients who have had an acute myocardial infarction with the application of stents.

\section{References}

1. Effects of oxygen ozone therapy on cardiac function in a patient with a prior myocardial infarction Sergio Pandolfi, Angelo Zammitti, Marianno Franzini, Vincenzo Simonetti, William Liboni, Luigi Valdenassi, Filippo Molinari, Ozone Therapy 2017; volume 2:6745
2. Lettieri B, Chiefari M, Vicario C. Cardiopatie ischemiche ed ozono-terapia. Giornate Meridionali di Ossigeno Ozono Terapia, Sorrento 9-10 Marzo 1991. Available from: www. angelipaolo.it/pdf/pag27.pdf 2.

3. Lettieri B. Efficacia dell'ozono terapia nella prevenzione della recidiva dell'infarto al miocardio. Acta Toxicol 1996;17:2-3.

4. Valdenassi L, Franzini M, Simonetti V, Ricevuti G. Ossigenoozono terapia: stimolo paradosso dell'ozono. Ozone Therapy 2016;1:2-4. 4.

5. Chang JD, Lu HS, Chang YF, Wang D. Ameliorative effect of ozone on cytokine production in mice injected with human rheumatoid arthritis synovial fibroblast cells. Rheumatol Int 2005;26:142-51. 5 .

6. Huth KC, Saugel B, Jakob FM, et al. Effect of aqueous ozone on the NF-kappaB system. J Dent Res 2007;86:451-6.

7. Bocci V, Bocci V. Studies on the biological effects of ozone: 10. Release of factors from ozonated human platelets. Mediators Inflamm 1999;8:205-9.

8. Bocci V. Is it true that ozone is always toxic? The end of a dogma. Toxicol Appl Pharmacol 2006;216:493-504.

9. Bocci V, Zanardi I, Travagli V. Oxygen/ozone as medical gas mixture. A critical evaluation of the various methods clarify espositive and negative aspects. Medical Gas Research 2011;1:6

10. Di Filippo, Marfella R, Capodanno P, et al. Acute oxygenozone administration to rats protects the heart from ischemia reperfusion infarct. Inflamm Res 2008;57:445-9. 13

11. Di Filippo C, Luongo M, Marfella R, et al. Oxygen/ ozone protects the heart from acute myocardial infarction through local increase of eNOS activity and endothelial progenitor cells recruitment. Naunyn Schmiedebergs Arch Pharmacol 2010;382:287-91. 19.

12. Barone A, Otero-Losada M, Grangeat AM, et al. Ozonetherapy protects from in-stent coronary neointimal proliferation. Role of redoxins. Int J Cardiol 2016;223:258-61.

13. Buyuklu M, Kandemir FM, Set T, Bakırcı EM, Degirmenci H, Hamur H, Topal E, Kucukler S, Turkmen K. Beneficial Effects of Ozone Therapy on Oxidative Stress, Cardiac Functions and Clinical Findings in Patients with Heart Failure Reduced Ejection Fraction. Cardiovasc Toxicol. 2017 Oct;17(4):426433. doi: 10.1007/s12012-017-9400-8.

14. Viebahn-Hänsler R. The use of ozone in medicine: mechanisms of action. Munich; Odrei. Publishers: 2003.

15. Borrelli E, Bocci V. Visual improvement following ozonetherapy in dry age related macular degeneration; a review. Med Hypothesis Discov Innov Ophthalmol 2013;2:47-51.

16. Merin O. Ozone administration reduces reperfusion injury in an isolated rat heart model. J Card Surg 2007;22:339-42. 